\title{
Intramural esophageal hematoma: an unusual cause of acute chest pain
}

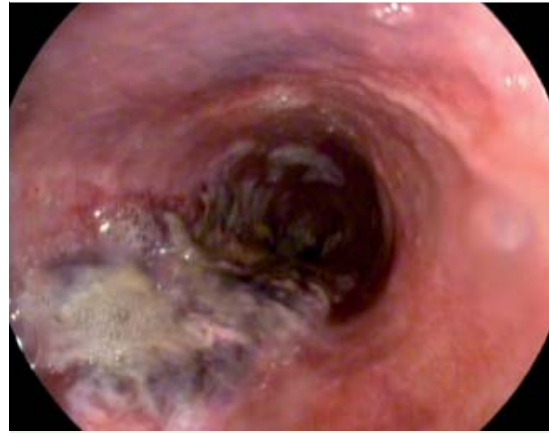

Fig. 1 One day after the onset of acute chest pain, a 79-year-old woman developed coffee ground vomitus. Esophagogastroduodenoscopy (EGD) showed a posterior esophageal hematoma.

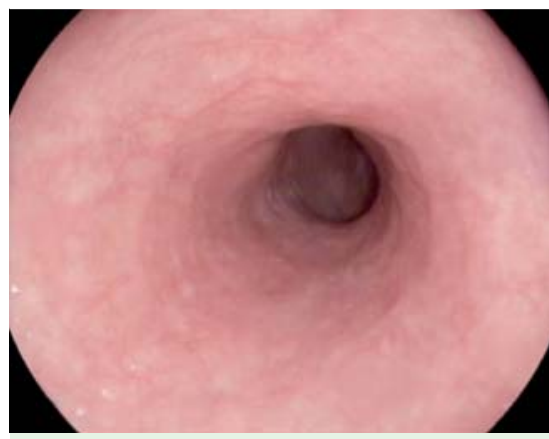

Fig. 3 Endoscopic view of the esophagus 12 weeks after initial endoscopy showing full resolution of the intramural esophageal hematoma (IEH).

A 79-year-old woman with a previous history of coronary artery bypass grafting presented with acute onset crushing central chest pain at rest. There were no preceding symptoms. On further questioning, the patient reported odynophagia at the time of symptom onset. She was hemodynamically stable with normal examination findings. Given her cardiac risk factors, she was initially treated as having acute coronary syndrome and received standard antiplatelet therapy. Serial electrocardiography and negative troponin test results excluded acute coronary syndrome.

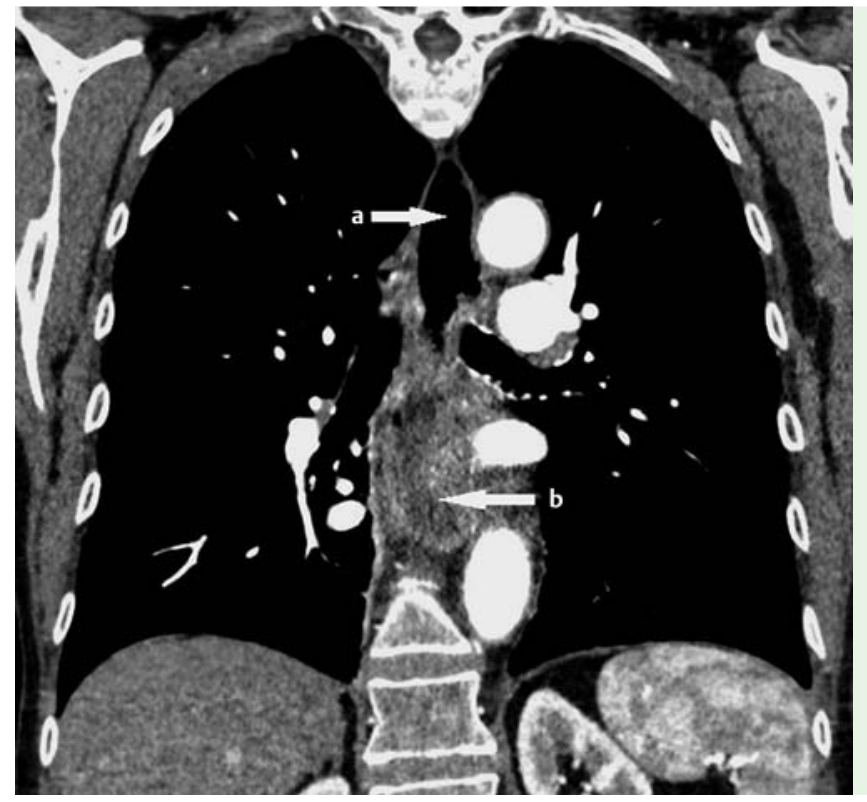

Fig. 2 A subsequent contrast-enhanced computed tomography (CT) scan of the thorax showed a distended esophagus (arrow a) containing echogenic material representing intramural hematoma (arrow b) but with no evidence of perforation.

One day after the onset of pain, the patient developed coffee ground vomitus. An urgent esophagogastroduodenoscopy (EGD) showed a posterior esophageal hematoma from $20 \mathrm{~cm}$ to the gastroesophageal junction ( Fig. 1). A subsequent computed tomography (CT) scan of the thorax showed a distended esophagus containing echogenic material representing hematoma but with no evidence of perforation ( Fig.2). The patient was managed conservatively with intravenous proton pump inhibitor therapy and slow introduction of a soft diet.

Intramural esophageal hematoma (IEH) is an uncommon, but important, cause of acute chest pain. Delayed or misdiagnosis is common resulting in inappropriate antiplatelet therapy. First described in 1968, it is defined as hemorrhage between the esophageal layers of the mucosa and muscularis propria, often involving a long segment of the esophagus [1,2]. Middle aged and elderly women are at higher risk [3]. Risk factors include Valsalva maneuver, antiplatelet therapy, instrumentation, and trauma. Classic symptoms are acute severe chest pain with associated vomiting, dysphagia or odynophagia $[3,4]$. EGD and CT scanning are useful in diagnosing IEH and excluding other pathologies. IEH is often located at the posterior esophagus with EGD showing a typical bluish submucosal hematoma causing a bulging of the overlying mucosa [2-4]. Conservative management consists of proton pump inhibitor therapy, a period of no oral intake followed by the reintroduction of a liquid and subsequently a soft diet $[3,4]$. Resolution of IEH occurs over 1 - 3 weeks (๑ Fig.3).

Endoscopy_UCTN_Code_CCL_1AB_2AC_3AH

Competing interests: None

\section{Benjamin Robert Disney, Shay-Anne Preece, Sauid Ishaq}

Department of Gastroenterology, Russells Hall Hospital, Dudley, West Midlands, United Kingdom 


\section{References}

1 Marks IN, Keet AD. Intramural rupture of the oesophagus. Br Med J 1968; 3: 536-537

2 Tay YK, Tay JY, Dandie $L$ et al. Intramural hematoma of the esophagus mimicking hemorrhaging esophageal cancer. Ann Gastroenterol 2013; 26: 74-76

3 McIntyre AS, Ayres R, Atherton J et al. Dissecting intramural haematoma of the oesophagus. OJM 1998; 91: 701 - 705

4 Cullen SN, McIntyre AS. Dissecting intramural haematoma of the oesophagus. Eur J Gastroenterol Hepatol 2000; 12: 1151-1162
Bibliography

Dol http://dx.doi.org/

10.1055/s-0034-1390712

Endoscopy 2014; 46: E607-E608

(C) Georg Thieme Verlag KG

Stuttgart · New York

ISSN 0013-726X
Corresponding author

Benjamin Robert Disney

Department of Gastroenterology

Russells Hall Hospital

Dudley

DY1 2HQ

United Kingdom

b.disney@nhs.net 